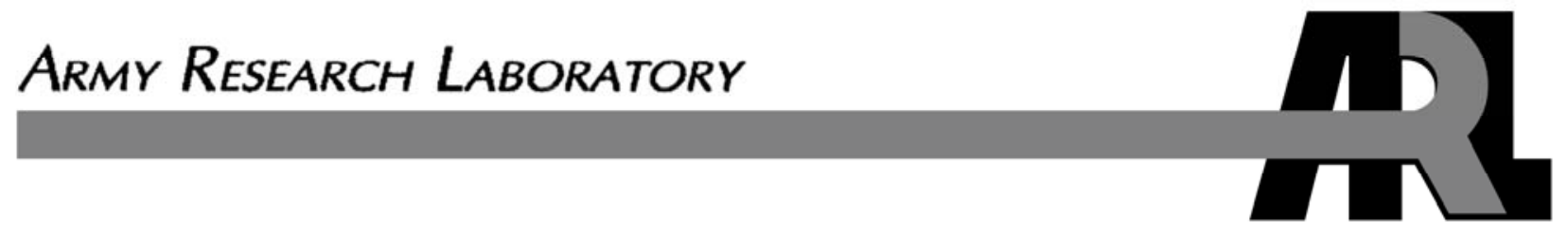

\title{
Extreme Scalability: Designing Interfaces and Algorithms for Soldier-Robotic Swarm Interaction
}

by Ellen Haas, MaryAnne Fields, Susan Hill, and Christopher Stachowiak 


\section{NOTICES}

\section{Disclaimers}

The findings in this report are not to be construed as an official Department of the Army position unless so designated by other authorized documents.

Citation of manufacturer's or trade names does not constitute an official endorsement or approval of the use thereof.

Destroy this report when it is no longer needed. Do not return it to the originator. 


\title{
Army Research Laboratory
}

Aberdeen Proving Ground, MD 21005-5069

ARL-TR-4800

April 2009

\section{Extreme Scalability: Designing Interfaces and Algorithms for Soldier-Robotic Swarm Interaction}

Ellen Haas, Susan Hill, and Christopher Stachowiak Human Research and Engineering Directorate, ARL

\author{
MaryAnne Fields
}

Vehicle Technology Directorate, ARL 


\section{REPORT DOCUMENTATION PAGE}

Form Approved OMB No. 0704-0188

Public reporting burden for this collection of information is estimated to average 1 hour per response, including the time for reviewing instructions, searching existing data sources, gathering and maintaining the data needed, and completing and reviewing the collection information. Send comments regarding this burden estimate or any other aspect of this collection of information, including suggestions for reducing the burden, to Department of Defense, Washington Headquarters Services, Directorate for Information Operations and Reports (0704-0188), 1215 Jefferson Davis Highway, Suite 1204, Arlington, VA 22202-4302. Respondents should be aware that notwithstanding any other provision of law, no person shall be subject to any penalty for failing to comply with a collection of information if it does not display a currently valid OMB control number.

PLEASE DO NOT RETURN YOUR FORM TO THE ABOVE ADDRESS.

\begin{tabular}{l|l|l} 
1. REPORT DATE (DD-MM- $Y Y Y Y)$ & 2. REPORT TYPE & 3. DATES COVERED (FrOm - To)
\end{tabular}

\begin{tabular}{l|l} 
April 2009 & Final
\end{tabular}

4. TITLE AND SUBTITLE

Extreme Scalability: Designing Interfaces and Algorithms for Soldier-Robotic

Swarm Interaction

6. AUTHOR(S)

Ellen Haas, MaryAnne Fields, Susan Hill, and Christopher Stachowiak

7. PERFORMING ORGANIZATION NAME(S) AND ADDRESS(ES)

U.S. Army Research Laboratory

ATTN: AMSRD-ARL-HR-SC

Aberdeen Proving Ground, MD 21005-5069

9. SPONSORING/MONITORING AGENCY NAME(S) AND ADDRESS(ES)

5a. CONTRACT NUMBER

5b. GRANT NUMBER

5c. PROGRAM ELEMENT NUMBER

5d. PROJECT NUMBER

5e. TASK NUMBER

5f. WORK UNIT NUMBER

8. PERFORMING ORGANIZATION REPORT NUMBER

ARL-TR-4800

10. SPONSOR/MONITOR'S ACRONYM(S)

11. SPONSOR/MONITOR'S REPORT NUMBER(S)

12. DISTRIBUTIONIAVAILABILITY STATEMENT

Approved for public release; distribution unlimited.

13. SUPPLEMENTARY NOTES

\section{ABSTRACT}

In theory, autonomous robotic swarms can be used for critical Army tasks (i.e., accompanying convoys); however, the Soldier controlling the swarm must be able to monitor swarm status and correct actions, especially in disrupted or degraded conditions. For this two-year Director's Research Initiative (DRI), we designed metacognition algorithms and Soldier-swarm display concepts to allow Soldiers to efficiently interact with a robotic swarm participating in a representative convoy mission. We used a potential field approach for swarm control because it scales easily to large heterogeneous swarms and allows users to dynamically alter swarm behavior by adjusting field parameters. The Soldier-swarm interface displayed swarm and convoy geospatial position; swarm health and communication; and convoy status information, using visual, auditory, and tactile combinations. We measured swarm metacognition by determining the proportion of time the simulated swarm could maintain a specific orbital ring around the convoy over six terrains in 13-min scenarios. We tested interface effectiveness in a laboratory study using 16 male Marines (volunteers) with a mean age of 19 years. The metacognition results showed that the swarm could maintain the pre-defined dispersion more than $85 \%$ of the time in each terrain. Using multimodal displays, Soldier workload decreased and performance increased (i.e., response time reduced).

\section{SUBJECT TERMS}

Auditory displays, spatial audio, 3-D audio, auditory warnings, visual search

\begin{tabular}{|c|c|c|c|c|c|}
\hline \multicolumn{3}{|c|}{ 16. SECURITY CLASSIFICATION OF: } & \multirow{2}{*}{$\begin{array}{l}\text { 17. LIMITATION } \\
\text { OF } \\
\text { ABSTRACT } \\
\text { UU }\end{array}$} & \multirow{2}{*}{$\begin{array}{l}\text { 18. NUMBER } \\
\text { OF } \\
\text { PAGES } \\
20\end{array}$} & \multirow{2}{*}{$\begin{array}{l}\text { 19a. NAME OF RESPONSIBLE PERSON } \\
\text { Ellen Haas } \\
\text { 19b. TELEPHONE NUMBER (Include area code) } \\
\text { (410) 278-5825 }\end{array}$} \\
\hline $\begin{array}{l}\text { a. REPORT } \\
\text { Unclassified }\end{array}$ & $\begin{array}{l}\text { b. ABSTRACT } \\
\text { Unclassified }\end{array}$ & $\begin{array}{l}\text { c. THIS PAGE } \\
\text { Unclassified }\end{array}$ & & & \\
\hline
\end{tabular}




\section{Contents}

List of Figures $\quad$ iv

List of Tables $\quad$ iv

$\begin{array}{lr}\text { 1. Objective } & 1\end{array}$

2. Approach 1

$\begin{array}{lr}3 . & \text { Results }\end{array}$

$\begin{array}{lr}\text { 4. Conclusions } & 9\end{array}$

$\begin{array}{ll}\text { 5. References } & 10\end{array}$

6. Transitions 11

List of Symbols, Abbreviations, and Acronyms $\quad 12$

$\begin{array}{ll}\text { Distribution List } & 13\end{array}$ 


\section{List of Figures}

Figure 1. Convoy and swarm on simulated terrain..........................................................

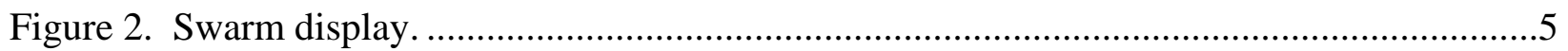

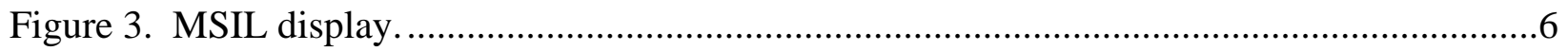

Figure 4. Mean swarm response time for each display type...................................................8

Figure 5. Mean NASA TLX workload rating for each swarm display type................................8

\section{List of Tables}

Table 1. Information presentation by display type for swarm display elements. ........................5 


\section{Objective}

Robotic swarms are arrays of small robots capable of autonomous travel and operation as a unit on land, sea, and air. In theory, the effective employment of robotic swarms can accomplish critical Army tasks, such as accompanying convoys, mapping battlefields, and clearing minefields. However, swarm control may become unstable when disturbed by unexpected changes in weather or terrain, degradation, attrition, or enemy actions, any of which could negatively impact or terminate the swarm's mission. A critical aspect of swarm control, especially in disrupted or degraded conditions, is Soldier-swarm interaction. The Soldier must remain cognizant of swarm operations, which is achieved through an interface that is used to monitor status and institute corrective actions during swarm supervision or over-watch. The growing body of human-robot interaction (HRI) research still has little to say about the design of Soldier-swarm interface displays and controls.

The objective of this two-year Director's Research Initiative (DRI) research plan was to design algorithms and devices that allowed Soldiers to efficiently interact with a robotic swarm participating in a representative convoy mission. The year one objectives were to (1) develop metacognition algorithms that enable swarm members to efficiently monitor changes in swarm status as they execute the mission and (2) provide display concepts that can efficiently and effectively communicate swarm status to Soldiers in challenging battlefield environments.

\section{Approach}

To realize their potential, robotic swarms must operate efficiently among members within the swarm as well as with external factors such as a Soldier/operator in a vehicle. Our approach consisted of defining swarm and mission characteristics, defining swarm control, providing metacognition to swarm members, designing a human-swarm interface, and then conducting a laboratory study to evaluate the swarm behavior algorithms and the Soldier-swarm display.

In defining swarm and mission characteristics, we used a simulated swarm because limitations of technology, budget, and time resources would not allow us to use a swarm with actual robots. However, using a swarm simulation had the added benefits of allowing the analysis of swarm size (number of members) and type (ground, air or micro systems), as well as the examination of different metacognition and Soldier-swarm interface technologies. We concentrated on swarm missions that require human oversight or supervision. In particular, we focused on a swarm that accompanies a manned convoy traveling on a road network to limit the number of simultaneous swarm activities to a small and predictable number. In our final approach, the swarm provided reconnaissance and searched for improvised explosive devices (IEDs) on and around the path of 
the convoy. The convoy contained four trucks that followed a sequence of user-defined waypoints, and our swarm consisted of 40 ducted fan aircraft. We used the Unreal Tournament 2004 game engine to conduct our simulation.

We used a potential field approach for swarm control, because it scales easily to large heterogeneous swarms and allows a user to dynamically alter swarm behavior by adjusting field parameters. The potential field used is a nonlinear sum of simpler fields, each of which attracts or repels the swarm from specific battlefield regions. In general, there is a field that controls the swarm's primary activity, a field that controls obstacle avoidance, and fields that control secondary activities (e.g., exploration of areas of interest). Due to space limitations, we will discuss the first vector field in depth and provide a short description of the potential field approach, which is further discussed in Barnes (1).

The swarm's primary activity was to remain in close proximity to the convoy. Suppose at some time, $t$, the geometric center of the convoy is at $\left(x_{c}, y_{c}\right)$ and that all the convoy vehicles are contained within a sequence of elliptical rings centered at $\left(\mathrm{x}_{\mathrm{c}}, \mathrm{y}_{\mathrm{c}}\right)$, with orientation $\phi$ and axis ratio $\lambda$. Suppose $\phi=0$, these rings can be considered as contours for the following surface:

$$
\mathrm{Z}(\mathrm{x}, \mathrm{y})=\mathrm{e}^{-\alpha\left(\left(\mathrm{x}-\mathrm{x}_{\mathrm{c}}\right)^{2}+\lambda\left(\mathrm{y}-\mathrm{y}_{\mathrm{c}}\right)^{2}\right)} ;
$$

the vector field will be derived from the gradient vectors for this surface.

To keep the swarm near the convoy, we designed a control scheme to attract swarm members to a specific orbital ring of the contour map specified by the inequality:

$$
\begin{aligned}
& \left(\mathrm{R}^{*}-\Delta \mathrm{R}_{\text {in }}\right)^{2}<\left(\mathrm{x}-\mathrm{x}_{\mathrm{C}}\right)^{2}+\lambda\left(\mathrm{y}-\mathrm{y}_{\mathrm{C}}\right)^{2}<\left(\mathrm{R}^{*}+\Delta \mathrm{R}_{\text {out }}\right)^{2}, \\
& \text { with } \mathrm{R}^{*}>0, \Delta \mathrm{R}_{\text {in }}>0 \text { and } \Delta \mathrm{R}_{\text {out }}>0 .
\end{aligned}
$$

Here $R^{*}$ determines the distance between the desired orbital ring and center of the surface and $\Delta R_{\text {out }}+\Delta R_{\text {in }}$ determines the width of that orbital ring. This control scheme will ensure that the swarm will remain within the orbital ring described in equation 2.

Suppose $(x, y)$ is a point outside the region described by the inequality of equation 2 . The vector,

$$
\left(\begin{array}{c}
v_{x} \\
v_{y}
\end{array}\right)=\frac{w_{\text {in }}(x, y)-w_{\text {out }}(x, y)}{\sqrt{\left(x-x_{c}\right)^{2}+\lambda^{2}\left(y-y_{c}\right)^{2}}}\left(\begin{array}{c}
\left(x-x_{c}\right) \\
\lambda\left(y-y_{c}\right)
\end{array}\right) \text {, for all }(x, y) \neq\left(x_{c}, y_{c}\right) \text {, }
$$

describes a vector of length $\mathrm{w}_{\text {in }}(\mathrm{x}, \mathrm{y})-\mathrm{w}_{\text {out }}(\mathrm{x}, \mathrm{y})$ that points to the highest point on the surface $Z$, $\left(\mathrm{x}_{\mathrm{c}}, \mathrm{y}_{\mathrm{c}}\right)$. We define $\mathrm{d}(\mathrm{x}, \mathrm{y})$ to be a weighted Euclidian distance:

$$
d(x, y)=\sqrt{\left(x-x_{c}\right)^{2}+\lambda^{2}\left(y-y_{c}\right)^{2}} .
$$


Let

$$
\mathrm{w}_{\text {out }}(\mathrm{x}, \mathrm{y})=\frac{1}{1+\mathrm{e}^{\alpha_{\text {out }}\left(\mathrm{d}(\mathrm{x}, \mathrm{y})-\left(\mathrm{R}^{*}+\Delta \mathrm{R}_{\text {out }}\right)\right)}}
$$

and

$$
\mathrm{w}_{\text {in }}(\mathrm{x}, \mathrm{y})=1-\frac{1}{1+\mathrm{e}^{\alpha_{\text {in }}\left(\mathrm{d}(\mathrm{x}, \mathrm{y})-\left(\mathrm{R}^{*}+\Delta \mathrm{Rin}\right)\right)}}
$$

with

$$
\alpha_{\text {out }}=-1 / \Delta \mathrm{R}_{\text {out }} \ln \left(\frac{1-\varepsilon}{\varepsilon}\right) \text { and } \alpha \text { in }=-1 / \Delta \mathrm{R}_{\text {in }} \ln \left(\frac{1-\varepsilon}{\varepsilon}\right)
$$

for some small $\varepsilon>0$. The functions $\mathrm{w}_{\text {out }}$ and $\mathrm{w}_{\text {in }}$ are sigmoid functions that approach 0 for points within the elliptical ring defined by the inequality in equation 2 .

Suppose $\left(\mathrm{P}_{\mathrm{x}}, \mathrm{P}_{\mathrm{y}}\right)$ is a point of interest, such as the location of a potential IED, an obstacle, or another vehicle. The vector

$$
\left(\begin{array}{l}
p_{x} \\
p_{y}
\end{array}\right)=-\frac{w(x, y)}{\sqrt{\left(x-P_{x}\right)^{2}+\left(y-P_{y}\right)^{2}}}\left(\begin{array}{c}
x-P_{x} \\
y-P_{y}
\end{array}\right)
$$

can attract swarm members to $\left(\mathrm{P}_{\mathrm{x}}, \mathrm{P}_{\mathrm{y}}\right)$ if $\mathrm{w}(\mathrm{x}, \mathrm{y})>0$ and repel swarm members from $\left(\mathrm{P}_{\mathrm{x}}, \mathrm{P}_{\mathrm{y}}\right)$ for $\mathrm{w}(\mathrm{x}, \mathrm{y})<0$. In our work, experimenter-assigned attractors were used to direct a portion of the swarm to interesting areas on the battlefield, which we designated as "hot spots." As we stated previously, the final vector field is a nonlinear sum of vectors defined by equations 3 and 8 .

To introduce metacognition into the swarm, we developed metrics that the swarm could use to describe its state. This task was high risk; if the metrics did not adequately describe the state of the swarm, the swarm would be uncontrollable. Our swarm metrics included the number of active members and status information for swarm members that split off the main group. We developed operational swarm metrics to provide information on how effectively the metacognition algorithms performed. One operational metric we developed was a measure of the ability of the swarm members to maintain an orbital ring with specific size limits around the entire convoy, while the convoy traveled over a terrain with experimenter-assigned waypoints. Team member discussion determined that in order for the swarm to provide reasonable protection to the convoy, the major axis of the swarm orbital ring was to be no larger than two convoy lengths and no smaller than one convoy length. We conducted an experiment to determine what proportion of time the simulated swarm was able to maintain the previously described orbital ring around the convoy while it travelled over six different terrains in 13-min scenarios. Prior to the experiment, the experimenter assigned waypoints and hot spots to different terrain locations. During the experiment, we noted what proportion of time the swarm 
consistently travelled with the convoy over all of the pre-defined waypoints, and what proportion of time the swarm members were attracted to the preset hotspots. Success in this area would indicate that the experimenter had successful pre-simulation control of swarm actions. Figure 1 shows a swarm dispersed around a convoy on a simulation terrain.

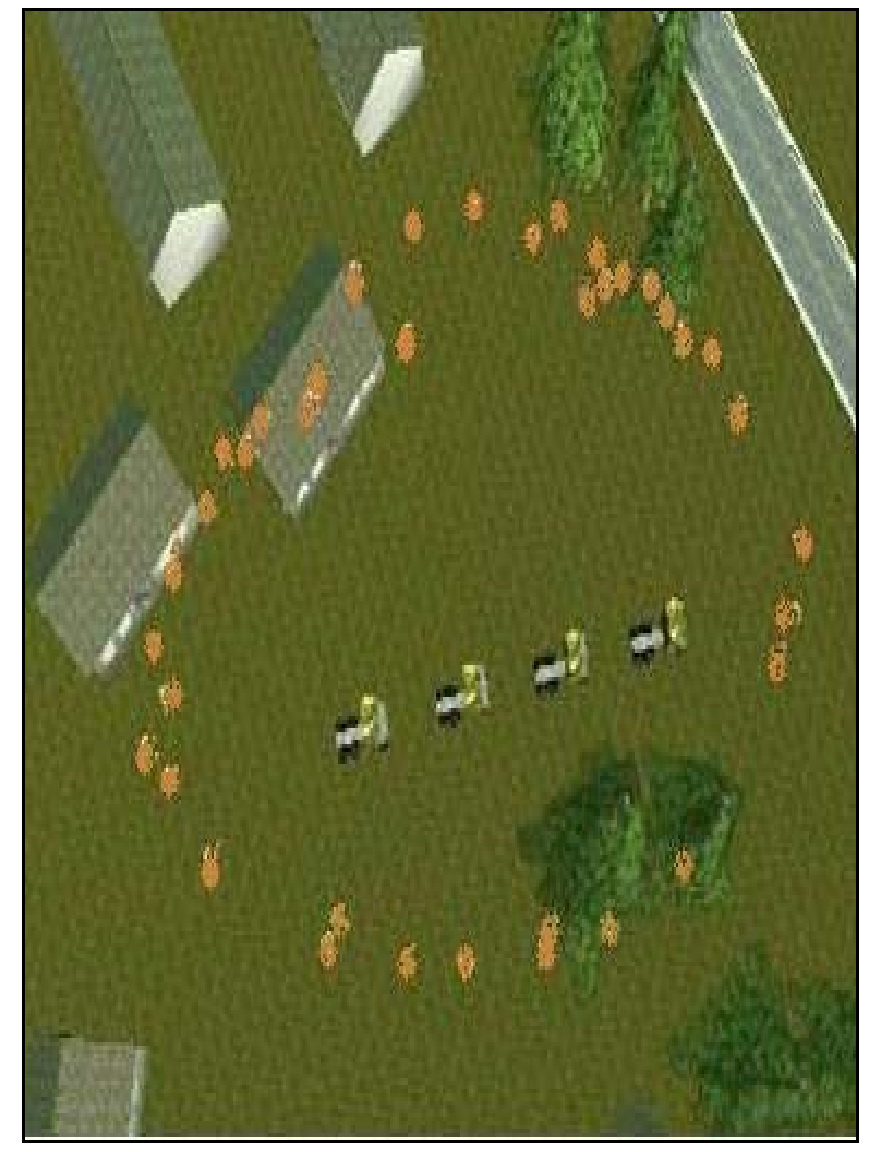

Figure 1. Convoy and swarm on simulated terrain.

To design the Soldier-swarm interface, we consulted with military subject matter experts and tested swarm behaviors to identify different types of information that the swarm might present to an operator with swarm oversight. This task was high risk, because information incorrectly displayed would make the display ineffective. The resulting visual swarm display is shown in figure 2. Swarm geospatial status showed the "live" swarm and convoy in an overhead view, as they traversed one of the six simulated terrains described previously. The other types of information (swarm health, swarm communication, and convoy status) are described in table 1. We added display information in different modalities (spatial, audio, and tactile cues), because research suggests that multimodal cues can increase awareness of surroundings and cue visual attention, especially when the user experiences a high visual load (2). Table 1 also shows our approach for presenting information in different modalities. All signals were triggered by changes in swarm health, swarm communication, and convoy status. 


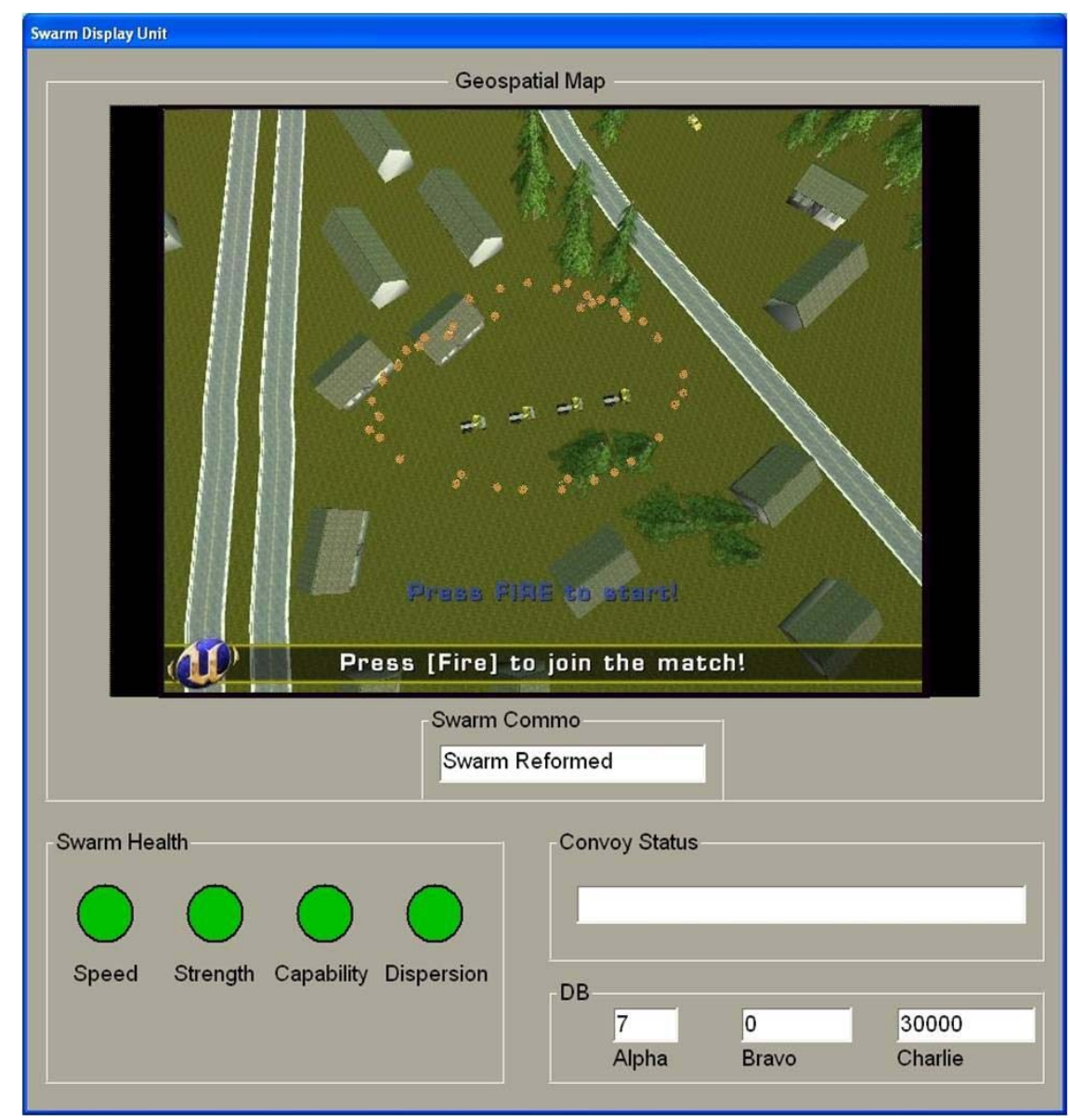

Figure 2. Swarm display.

Table 1. Information presentation by display type for swarm display elements.

\begin{tabular}{|c|c|c|c|c|}
\hline $\begin{array}{l}\text { Swarm } \\
\text { Display }\end{array}$ & $\begin{array}{c}\text { Visual } \\
(\mathrm{V})\end{array}$ & $\begin{array}{l}\text { Visual + Audio } \\
\text { (VA) }\end{array}$ & $\begin{array}{c}\text { Visual + Tactile } \\
\text { (VT) }\end{array}$ & $\begin{array}{c}\text { Visual + Audio + Tactile } \\
\text { (VAT) }\end{array}$ \\
\hline Swarm health & $\begin{array}{l}\text { Status lights (green, } \\
\text { yellow, red) for } \\
\text { swarm speed, } \\
\text { strength, capability, } \\
\text { and dispersion. }\end{array}$ & $\begin{array}{l}\text { Visual cues plus recorded } \\
\text { spoken messages (e.g., } \\
\text { "Dispersion Yellow”). } \\
\text { Speech (audio) presented } \\
\text { at } 315^{\circ} \text { from center front. }\end{array}$ & $\begin{array}{l}\text { Visual cues plus } \\
\text { vibrating tactor at } \\
315^{\circ} \text { from center } \\
\text { front. }\end{array}$ & $\begin{array}{l}\text { Visual cues plus recorded } \\
\text { spoken messages } \\
\text { presented at } 315^{\circ} \text { from } \\
\text { center front. }\end{array}$ \\
\hline $\begin{array}{l}\text { Swarm } \\
\text { communications } \\
\text { (commo) }\end{array}$ & $\begin{array}{l}\text { Text box shows text } \\
\text { messages relating to } \\
\text { swarm state or } \\
\text { activities (e.g., } \\
\text { "Swarm Reformed"). }\end{array}$ & $\begin{array}{l}\text { Visual cues plus recorded } \\
\text { spoken messages (e.g., } \\
\text { "Swarm Reformed”) } \\
\text { presented at } 0^{\circ} \text { from } \\
\text { center front. }\end{array}$ & $\begin{array}{l}\text { Visual cues plus } \\
\text { vibrating tactor at } \\
0^{\circ} \text { from center } \\
\text { front. }\end{array}$ & $\begin{array}{l}\text { Visual cues plus recorded } \\
\text { spoken messages } \\
\text { presented at } 0^{\circ} \text { from } \\
\text { center front. }\end{array}$ \\
\hline Convoy status & $\begin{array}{l}\text { Text box at lower } \\
\text { right shows text } \\
\text { messages relating to } \\
\text { convoy (e.g., } \\
\text { "Convoy Off Road"). }\end{array}$ & $\begin{array}{l}\text { Visual cues, plus } \\
\text { recorded spoken } \\
\text { messages (e.g., “Convoy } \\
\text { Off Road”) presented at } \\
45^{\circ} \text { from center front. }\end{array}$ & $\begin{array}{l}\text { Visual cues, plus } \\
\text { vibrating tactor at } \\
45^{\circ} \text { from center } \\
\text { front. }\end{array}$ & $\begin{array}{l}\text { Visual cues, plus recorded } \\
\text { speech messages at } 45^{\circ} \\
\text { from center front. }\end{array}$ \\
\hline
\end{tabular}


We conducted a laboratory study to evaluate the swarm display interface. Sixteen male Marines with a mean age of 19 years from the Marine Detachment at Aberdeen Proving Ground, MD, served as volunteer participants. Each Marine performed the task of monitoring the swarm display and responding to the display signals when they occurred by pressing one of three corresponding buttons on a pushbutton display and then verbally telling the experimenter which swarm display signal they recognized (e.g., "Dispersion Yellow”). The buttons on the pushbutton display corresponded to one of the three signal types (swarm health, swarm communication, convoy status). To emulate the multitasking environment found in military missions, the Marines simultaneously performed a second task. In the second task, Marines used a modified Robotic Collaborative Technology Alliance (CTA) simulation integration laboratory (MSIL) task to perform four different cursor control tasks (click and hold, drag and drop, point to point, and text selection) that resembled robotic planning tasks on a screen resembling the SIL (shown in figure 3). The Marines were told to perform both tasks as quickly accurately as they could, but to respond to the swarm display signals as soon as they occurred. Audio cues were played over Sony headphones. Tactile cues were experienced from one of three Engineering Acoustics Incorporated (EAI) tactors mounted in a belt worn on the participant's torso.

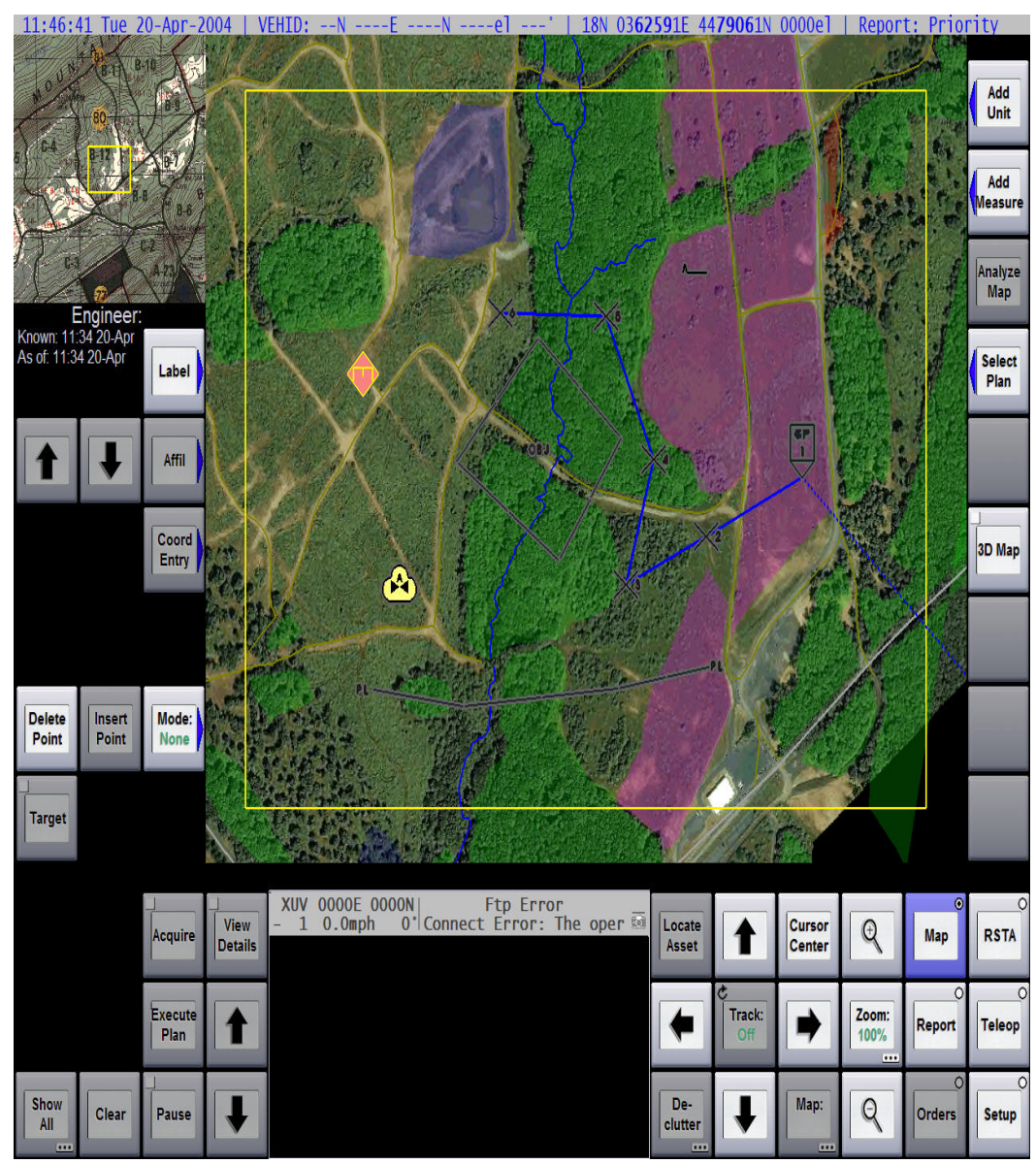

Figure 3. MSIL display. 
The independent variables were swarm display information and swarm display type. Swarm display information was swarm health, swarm communication, and convoy communication. Swarm display types were visual display only (V); visual display supplemented with audio cues (VA); visual display supplemented with tactile cues (VT); and visual display supplemented with audio and tactile cues (VAT). The dependent measures included participant response times to swarm display and SIL tasks. The National Aeronautics and Space Administration (NASA) Task Load Index (TLX) rating scale was used to evaluate workload (3). A final questionnaire allowed each participant to compare display types and to provide additional comments. We had two experimental hypotheses: (1) That the level and type of information communicated by the display would furnish adequate information for a convoy scenario, and (2) that visual swarm displays supplemented by audio and/or tactile information (visual + audio, visual + tactile, and visual + audio + tactile displays) would communicate swarm activities to the Soldier more quickly and accurately than the swarm display with visual information only.

\section{Results}

The results of the metacognition experiment indicated that the swarm was able to maintain the pre-defined dispersion more than $85 \%$ of the time on each of the six simulation terrains. In addition, the experimenter noted that the swarm consistently travelled with the convoy over all of the pre-defined waypoints, and the swarm members were attracted to all of the preset hotspots. This indicated that the experimenter had successful pre-simulation control of swarm actions.

Swarm display experiment accuracy data indicated that 99.9\% of all signals were correctly detected and recognized. An SPSS mixed model analysis of variance (ANOVA) performed on the swarm display response time data and on the workload data indicated significant main effects for display type $(p=0.000)$. Bonferroni post-hoc tests indicated that Marines using multimodal cues (VA, VT, or VAT) had a significantly shorter response time and lower workload than those using visual cues alone. There were no other significant differences. Figures 4 and 5 show means for display type for response time and workload. The largest mean difference in response times (between V and VAT displays) was $1.5 \mathrm{~s}$, which may make a practical difference in U.S. Army operations in which seconds count. Error bars for both figures represent $95 \%$ confidence intervals. Marine comments indicated that their preferences were consistent with the performance and workload scores: 73\% preferred the VAT display over other display types, 20\% preferred the VA display, and 7\% preferred the VT display. The V display was least preferred by $73 \%$ of the Marines. All Marines stated that they liked the level and type of information content of the displays. Many suggested that the swarm communication display provide additional information about size and location of IEDs. Suggestions were made about swarm formations and operational concepts. The Marines became very engaged in the swarm tasks and liked the idea of employing swarms in future military operations. 


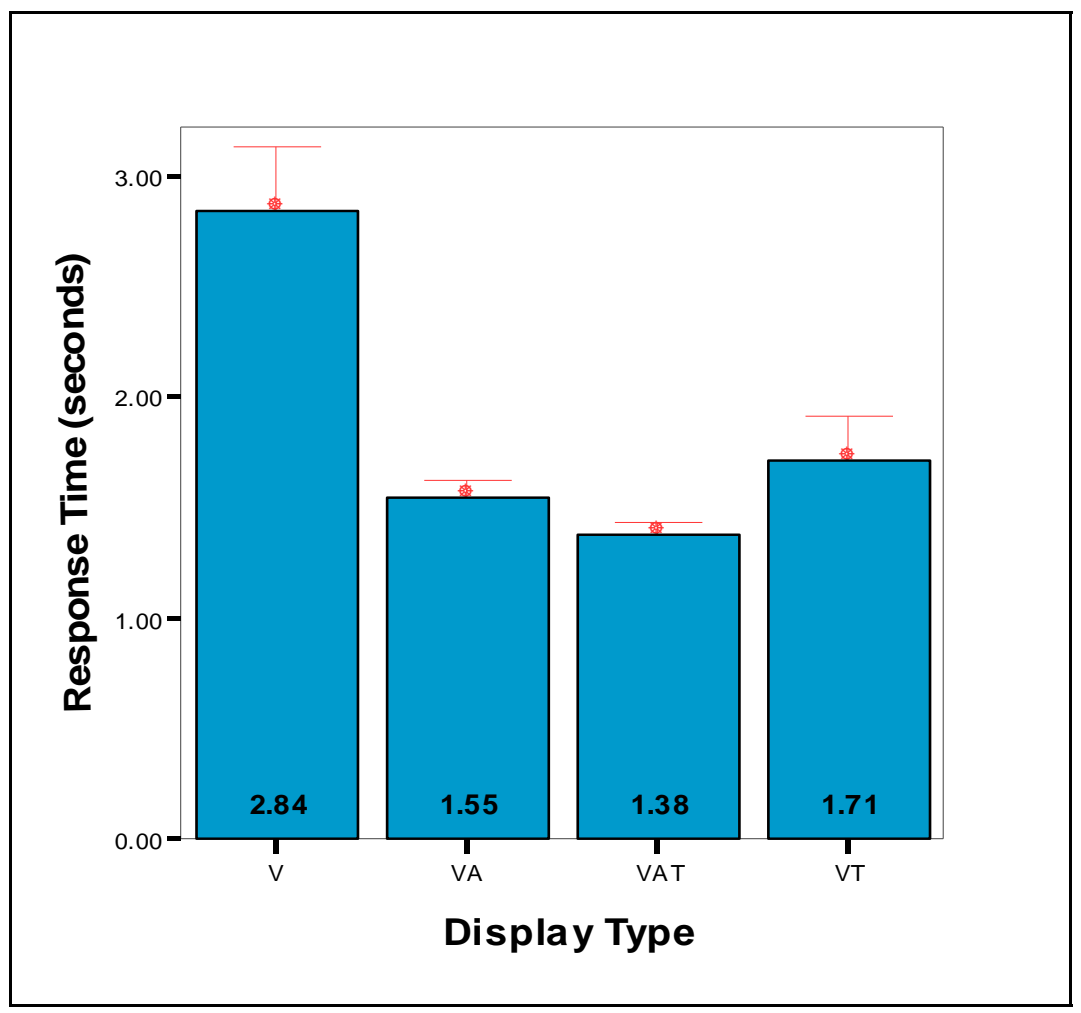

Figure 4. Mean swarm response time for each display type.

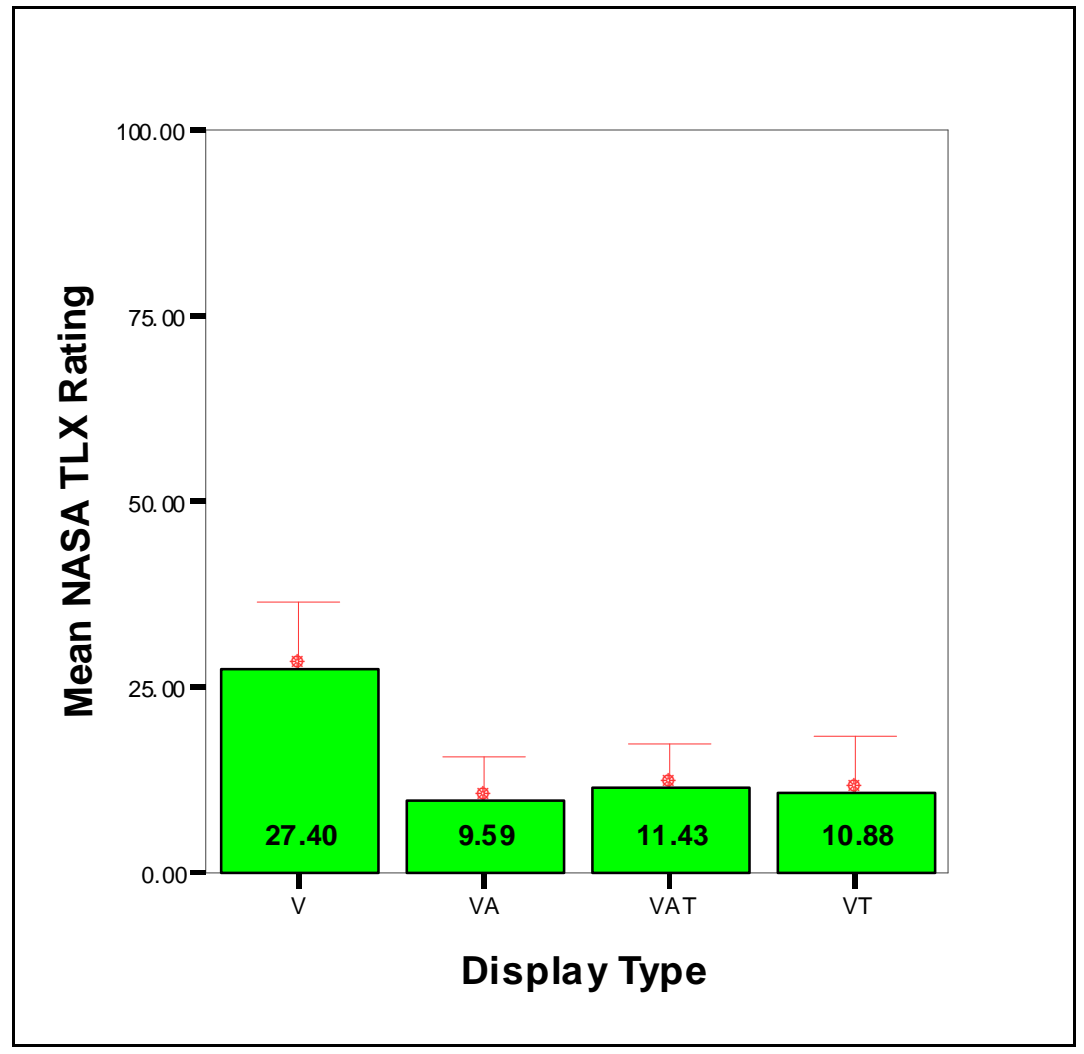

Figure 5. Mean NASA TLX workload rating for each swarm display type. 


\section{Conclusions}

Most of the first-year objectives of this two-year DRI research plan were met. We successfully defined a 40-member simulated swarm to accompany a four-member convoy, and successfully developed metacognition algorithms that enabled swarm members to efficiently monitor changes in swarm status as they executed six different convoy missions. We determined that the experimenter could successfully assign waypoints and hot spots, indicating that presimulation control of swarm actions was possible. We successfully designed a human-swarm interface that allowed Marines to efficiently interact with a robotic swarm participating in a representative convoy mission. We succeeded in providing swarm display information concepts that could efficiently and effectively communicate swarm-provided information to Marines by defining specific information demanded for a Soldier swarm supervisor. The Marines in our experiment indicated that the information provided by the interface permitted them to interact with the swarm as one homogeneous entity, rather than an entity with 40 different members. We were also successful in developing different multimodal display concepts for the human-display interface.

Two of our DRI goals were not completely met:

1. We still need to further define non-operational criteria for swarm metacognition.

2. Swarm control by a human during swarm operations has not yet been accomplished.

These high-risk tasks will be attempted in the second year of the DRI, which will deal with expanded swarm strategies for more complex swarm operations and with real-time human interfaces for swarm control. Elements of our completed research (i.e., our observations regarding the limitations of our current metacognition algorithms and Marine suggestions regarding relevant swarm control tasks) will serve as a basis from which to approach these second-year tasks. 


\section{References}

1. Barnes, L.; Fields, M. A.; Valavanis, K. Unmanned Ground Vehicle Swarm Formation Control Using Potential Fields, Mediterranean Conference on Control \& Automation 2007, 27-29 June 2007, pp 1-8.

2. Shilling, R. D.; Shinn-Cunningham, B. Virtual Auditory Displays. In Handbook of Virtual Environments, K. Stanney, Ed.; Erlbaum: Mahwah, NJ, 2002, pp 65-92.

3. Hart, S.; Staveland, L. Development of NASA-TLX (Task Load Index): Results of Empirical and Theoretical Research. In Human Mental Workload, P. Hancock and N. Meshkati, Eds.; Elsevier Science Publishers: North-Holland, Amsterdam, 1988. 


\section{Transitions}

Our work will be used to support our year two DRI research in which Soldiers will be able to modify the behavior of the swarm. It will also be used for studies of heterogeneous swarms (ground vehicles and helicopters) in future U.S. Army Research Laboratory (ARL) and University of Texas in Arlington research. In addition, the Micro Autonomous Systems and Technology (MAST) CTA has shown interest in the algorithms developed for the simulated swarm.

A technical report is being prepared, as well as papers for submission at conferences, including the Human Factors and Ergonomics Society and the Association for Computing Machinery (ACM)/Institute of Electrical and Electronics Engineers (IEEE) Human Robot Interaction conferences. 


\section{List of Symbols, Abbreviations, and Acronyms}

ACM Association for Computing Machinery

CTA Collaborative Technology Alliance

DRI Director's Research Initiative

EAI Engineering Acoustics Incorporated

HRI human-robot interaction

IEDs improvised explosive devices

IEEE Institute of Electrical and Electronics Engineers

MAST Micro Autonomous Systems and Technology

MSIL modified simulation integration laboratory

NASA National Aeronautics and Space Administration

SIL simulation integration laboratory

TLX Task Load Index

V visual display only

VA visual display supplemented with audio cues

VAT visual display supplemented with audio and tactile cues

VT visual display supplemented with tactile cues 


\section{Copies Organization}

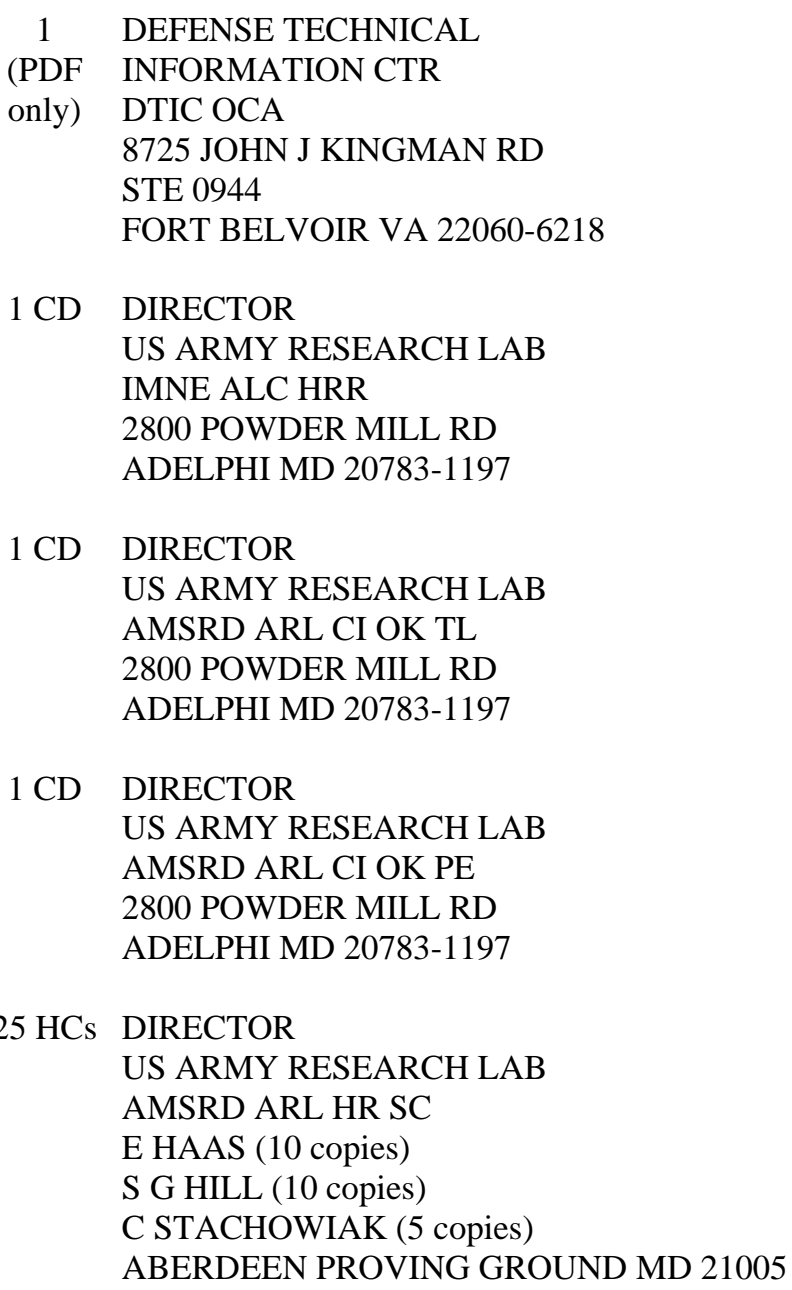

\section{ABERDEEN PROVING GROUND}

1 CD DIR USARL

$10 \mathrm{HCs}$ AMSRD ARL CI OK TP (BLDG 4600)

AMSRD ARL VT UV

M FIELDS (10 copies)

TOTAL: 40 (1 ELEC, 4 CDs, 35 HCs) 
INTENTIONALLY LEFT BLANK. 